\title{
VIDEO EDUKASI ANIMASI 2 DIMENSI MENGENAI BAHAYA MERKURI TERHADAP MASYARAKAT KABUPATEN LOMBOK TENGAH SEBAGAI DAMPAK PENAMBANGAN EMAS ILEGAL
}

\author{
I Made Marthana Yusa ${ }^{1}$, Laksminta Rukmi \\ 1,2Peminatan Desain Grafis dan Multimedia, \\ Program Studi Teknik Informatika, STMIK STIKOM Indonesia \\ made.marthana@gmail.com / made.marthana@stiki-indonesia.ac.id ${ }^{1}$, laxmy26@gmail.com²
}

\begin{abstract}
Abstrak
Merkuri adalah salah satu jenis logam berat yang banyak ditemukan di alam dan tersebar dalam batuan, tanah, air dan udara sebagai senyawa anorganik dan organik. Merkuri dapat dimanfaatkan dalam berbagai bidang industri, salah satunya industri emas. Pengelolaan limbah hasil industri pengolahan emas yang tidak sesuai dengan prosedur yang baik dan benar akan menyebabkan pencemaran lingkungan. Merkuri yang telah mengontaminasi lingkungan dalam jangka waktu panjang akan membawa dampak buruk bagi kesehatan manusia yang sering berinteraksi dengan bahan merkuri ini. Dalam penelitian ini, dilakukan perancangan video berbasis animasi 2 dimensi, sebagai salah satu rekomendasi solusi edukasi, untuk pencegahan dampak kesehatan, akibat pencemaran lingkungan oleh merkuri di Lombok Tengah. Dari hasil penelitian didapatkan fakta bahwa responden yang terdiri dari staf Konservasi dan Sumber Daya Alam serta staf Pengawasan dan Pengendalian Lingkungan Kantor Lingkungan Hidup Kabupaten Lombok Tengah menilai video edukasi berbasis animasi 2 dimensi yang dihasilkan sangat baik dari segi desain maupun penyampaian informasinya. Video ini juga bermanfaat untuk mengedukasi masyarakat penambang emas di Lombok Tengah agar lebih mewaspadai merkuri dan bahayanya, juga menghargai kesehatan diri dan keselamatan kerja.
\end{abstract}

Kata Kunci: Animasi 2 Dimensi, Bahaya Merkuri, Merkuri, Metil Merkuri, Video Edukasi

\begin{abstract}
Mercury is one of the heavy metals found in nature and spread in rocks, soil, water and air as inorganic and organic compounds. Mercury can be utilized in various industrial fields, one of which is the gold industry. Waste management of gold processing industry that is not in accordance with good and correct procedures will cause environmental pollution. Mercury that has been contaminating the environment over the long term will have adverse effects on human health that often interact with these mercury ingredients. A 2-dimensional animation based video has been designed in this research, as one recommendation of educational solution, for the prevention of health impact, due to environmental pollution by mercury in Central Lombok. From the research results obtained the fact that respondents consisting of staff Conservation and Natural Resources and staff of Environmental Monitoring and Control Environment Office of Lombok Tengah District assessed 2-dimensional animation based animation videos produced very well in terms of design and delivery of information. This video is also useful to educate the gold miners community in Central Lombok to be more aware of mercury and its dangers, also appreciate the Occupational Health and Safety.
\end{abstract}

Keywords: 2 Dimensional Animation, Mercury, Methyl Mercury, Educational Video 


\section{PENDAHULUAN}

\subsection{Latar Belakang}

Merkuri (air raksa, $\mathrm{Hg}$ ) adalah salah satu jenis logam yang banyak ditemukan di alam dan tersebar dalam batu-batuan, biji tambang, tanah, air dan udara sebagai senyawa anorganik dan organik (Sitepu, 2004). Umumnya kadar merkuri dalam tanah, air dan udara relatif rendah. Berbagai jenis aktivitas manusia dapat meningkatkan kadar ini, salah satu contohnya adalah aktivitas penambangan yang dapat menghasilkan merkuri sebanyak 10.000 ton per tahun (Sitepu, 2004).

Berdasarkan laporan hasil pengujian sianida dan merkuri di sepanjang sungai Koko Dalam di Desa Sepakek, Desa Sintung dan Desa Ubung, Kabupaten Lombok Tengah tahun 2013, dapat diketahui bahwa konsentrasi merkuri pada beberapa titik pengambilan sampel air Sungai Koko Dalam berada pada nilai 0,002 mg/L, sedangkan baku mutu air untuk parameter merkuri sebesar 0,002 mg/L. Fakta tersebut mengungkap bahwa kadarnya telah melewati ambang batas baku mutu untuk air minum sebesar $0,001 \mathrm{mg} / \mathrm{L}$.

Sekali merkuri masuk ke badan air/ lumpur, maka melalui aktivitas bakteri tertentu, merkuri berubah menjadi metil merkuri yang lebih berbahaya. Toksisitas merkuri berbeda sesuai bentuk kimianya, misalnya merkuri inorganik bersifat toksik pada ginjal, sedangkan merkuri organik seperti metil merkuri bersifat toksik pada sistem saraf pusat (Subanri, 2008).

Melihat begitu banyak resiko yang ditimbulkan oleh merkuri, maka diperlukan solusi untuk penanggulangannya, khususnya dalam upaya pencegahan dampak merkuri terhadap kesehatan masyarakat. Pemerintah Daerah Kabupaten Lombok Tengah telah melakukan berbagai upaya dalam menyosialisasikan bahaya merkuri ini kepada masyarakat, namun belum mendapatkan hasil yang optimal/sesuai harapan.

Media sosialisasi alternatif diperlukan untuk memberikan informasi bahaya merkuri dengan persuasi edukatif, dalam memberikan pemahaman, dengan materi yang disampaikan sederhana dan menarik perhatian. Salah satu media yang representatif dan memenuhi profil media sosialisasi yang dibutuhkan adalah video edukasi berbasis animasi 2D. Penelitian ini bertujuan untuk memenuhi kebutuhan Pemerintah Daerah Kabupaten Lombok Tengah akan media edukasi yang mampu memberikan informasi awal mengenai bahaya pencemaran merkuri, dan mempersuasi masyarakat penambang emas di Lombok Tengah untuk melakukan langkah-langkah preventif dalam mencegah dampak pencemaran merkuri pada kesehatan mereka.

\subsection{Perancangan Animasi 2 Dimensi}

Animasi adalah paparan urutan gambar yang antara urutan gambar satu dengan setelahnya terdapat sedikit perbedaan untuk menghasilkan satu pergerakan secara berkelanjutan. Animasi merupakan satu teknologi yang menyebabkan gambar seolaholah hidup, dapat bergerak, beraksi dan bersuara (Thomas dan Johnston, 1995). Animasi sebagai media audio-visual yang mengandung unsur edukasi, entertainment (hiburan), memiliki potensi besar untuk menarik perhatian pemirsa dalam 
menghilangkan kejenuhan akan metode sosialisasi sebelumnya yang monoton (Yusa, 2017). Selain itu, kelebihan animasi dibandingkan media yang lain adalah dapat digunakan sebagai media bantu yang menjelaskan atau memaparkan suatu materi/issue yang sangat rumit dan kompleks melalui gambar, gerakan dan suara secara sederhana (Blair, 1994). Animasi mempunyai alur penyampaian yang sedemikian rupa sehingga penonton mengikuti semua yang disampaikan dalam alur cerita dari animasi tersebut (Purnama, 2013).

Menurut Sitepu, animasi 2D adalah animasi yang direpresentasikan bentuknya dalam 2 sistem koordinat bidang yakni tinggi $(\mathrm{y})$ dan lebar ( $\mathrm{x}$ ). Sistem koordinat adalah dimensidimensi koordinat yang membentuk citra grafis. Di dalam 2D, gambar hanya bisa bergerak ke dua arah yaitu ke kanan dan ke kiri atau ke atas dan ke bawah. Objek citra grafis 2D tidak bisa dipandang dari sudut perspektif yang lain, memutarnya, dan sebagainya (Sitepu, 2005).

Perancangan animasi-seperti perancangan game-membutuhkan kolaborasi sinergis antara bidang seni, sains, dan teknologi. Gerak pada animasi yang berpola, teratur, atau random membutuhkan algoritma yang bisa memudahkan animator dalam mewujudkan animasi yang logis, efektif, efisien, namun juga estetis dan canggih dengan dukungan seni dan pemanfaatan teknologi terkini (Yusa, 2016). Perancangan animasi meliputi proses pra produksi (pre production), produksi (production), dan pasca produksi (post production), dimana setiap alur kerja (pipeline-nya) dikeola agar project animasi bisa berjalan teratur dan selesai dengan baik dan benar.

\subsection{Merkuri / Hydrargyrum $(\mathrm{Hg})$ dan Dampaknya}

Menurut Sitepu (2004), merkuri atau air raksa merupakan salah satu logam yang berbentuk cair, berwarna perak/silver, dilambangkan dengan $\mathrm{Hg}$ (Hydrargyrum), menempati urutan (NA) 80, dan mempunyai bobot atom (BA 200.59). Secara umum, sifat-sifat merkuri adalah sebagai berikut:

1. Berwujud cair pada suhu kamar $\left(25^{\circ} \mathrm{C}\right)$ dengan titik beku paling rendah sekitar $39^{\circ} \mathrm{C}$.

2. Pada temperatur $396^{\circ} \mathrm{C}$ telah terjadi pemuaian secara menyeluruh.

3. Merupakan logam yang paling mudah menguap jika dibandingkan dengan logamlogam yang lain.

4. Tahanan listrik yang dimiliki sangat rendah, sehingga menempatkan merkuri sebagai logam yang sangat baik untuk menghantarkan daya listrik.

5. Dapat melarutkan bermacam-macam logam untuk membentuk alloy yang disebut juga dengan amalgam.

Merkuri merupakan unsur yang sangat beracun bagi semua makhluk hidup, baik itu dalam bentuk unsur tunggal (logam) ataupun dalam bentuk persenyawaan (Palar, 2012).

Pengaruh toksisitas merkuri pada manusia bergantung pada bentuk, komposisi merkuri, rute masuknya ke dalam tubuh dan lamanya terpapar. Bentuk merkuri organik seperti metil merkuri, sekitar 99\% diabsorpsi oleh dinding usus, hal ini jauh 
lebih besar daripada bentuk inorganik $\left(\mathrm{HgCl}_{2}\right)$ yang hanya sekitar $10 \%$. Akan tetapi, bentuk merkuri organik ini kurang bersifat korosif daripada bentuk inorganik. Bentuk organik tersebut juga dapat menembus barier darah dan plasenta sehingga dapat menimbulkan pengaruh teratogenik dan gangguan saraf. Selain itu, pengaruhnya juga tidak spesifik terhadap organ tertentu. Palar dalam bukunya yang berjudul Pencemaran dan Toksikologi Logam Berat menjelaskan bahwa pada wanita-wanita hamil, yang terpapar oleh senyawa alkil-merkuri dapat menyalurkan senyawa tersebut pada janin yang dikandungnya (Palar, 2012). Senyawa alkil-merkuri tersebut masuk bersama makanan melewati plasenta karena dibawa oleh peredaran darah ke janin. Kontaminasi yang disebabkan oleh alkil-merkuri ini dapat merusak otak janin, sehingga pada saat lahir, bayi menjadi cacat, seperti kasus kontaminasi merkuri di Minamata, Jepang.

\subsection{Penambangan Emas Ilegal di Kabupaten Lombok Tengah}

Sejak Tahun 2011 di Kabupaten Lombok Tengah telah terjadi penambangan emas ilegal. Dikatakan ilegal karena aktivitas penambangan tersebut tidak memiliki izin dari Pemerintah Kabupaten Lombok Tengah. Lokasi pengambilan batuan emas terdapat di dua lokasi yaitu di Dusun Aur Manis, Desa Bilelando, Kecamatan Praya Timur dan Desa Prabu, Kecamatan Pujut. Batuan-batuan mengandung emas yang telah digali selanjutnya dibawa ke lokasi pengolahan batuan yang tersebar di beberapa kecamatan di Kabupaten Lombok Tengah. Kecamatan dengan jumlah pengolah batuan emas terbanyak adalah Kecamatan Pringgarata.

Berdasarkan informasi dari Kantor Lingkungan Hidup Kabupaten Lombok Tengah sumber batuan emas tidak saja berasal dari Kabupaten Lombok Tengah tetapi juga berasal dari Kabupaten Lombok Barat dan bahkan ada yang dibawa dari Kabupaten Sumbawa Barat. Pengolahan emas dilakukan dengan dua cara yaitu amalgamasi (gelondong) dan sianidasi (tong). Tidak hanya emas hasil gelondongan saja yang dapat dijadikan komoditi, melainkan tailing yang merupakan limbah hasil penggelondongan yang masih mengandung emas juga dijual lagi, untuk dilakukan pengolahan lanjutan, untuk menangkap sisa logam yang masih berada pada tailing tersebut.

\subsection{Tinjauan Penelitian Pendahulu}

Terdapat banyak penelitian yang menggunakan media Animasi 2D sebagai media edukasi dalam penyampaian isu/permasalahan, kemudian menyampaikan mekanisme/cara penanggulangannya. Dari sekian banyak artikel, dikaji penelitian terpilih yaitu tulisan Yusa dan Saputra dengan judul "Pemanfaatan Animasi 2 Dimensi Model Infografik dalam Perancangan Video Iklan Layanan Masyarakat Tentang Pengolahan Sampah Rumah Tangga di Denpasar" (Yusa dan Saputra, 2016).

Pada penelitian tersebut, diungkapkan penyebab permasalahan sampah di Denpasar yaitu sampah rumah tangga dan akibatnya (banjir). Kemudian diungkap juga mekanisme penanggulangannya dengan 3R (reduce, reuse dan recycle). Penyampaian $3 R$ dikonsepkan sederhana, efektif dan efisien dengan media video animasi 2D dan terbukti berhasil dicerna dengan mudah oleh audience. Bukti tersebut menjadi dasar 
penguat dalam penggunaan media video animasi 2D sebagai media edukasi. Model infographic motion graphic yang digunakan pada penelitian Yusa dan Saputra diadaptasi pada penelitian ini.

Selanjutnya, penelitian Saputro, G.E., Haryadi, T. and Yanuarsari, D.H. (Saputro, Haryadi dan Yanuarsari, 2016) diacu dalam kaitannya dengan persamaan nilai-nilai safety (keselamatan) pada materi objek penelitian. Poin penting yang dicermati pada penelitian tersebut adalah penggunaan konsep digital storytelling, dan model komunikasi SMCR (Source, Message, Channel, and Receiver) yang kemudian diadaptasi pada penelitian ini.

\section{METODE PENELITIAN}

Penelitian ini dilakukan melalui langkah-langkah metodologis, yang dimulai dari pengumpulan data, perancangan animasi, hingga evaluasi kelayakan dan tingkat penerimaan video edukasi animasi yang dihasilkan. Langkah-langkah metodologis penelitian kemudian dikembangkan dan disempurnakan sesuai langkah prosedural perancangan animasi yang meliputi proses pra produksi (pre production), produksi (production), dan pasca produksi (post production). Langkah metodologis perancangan animasi dijabarkan pada gambar 1.

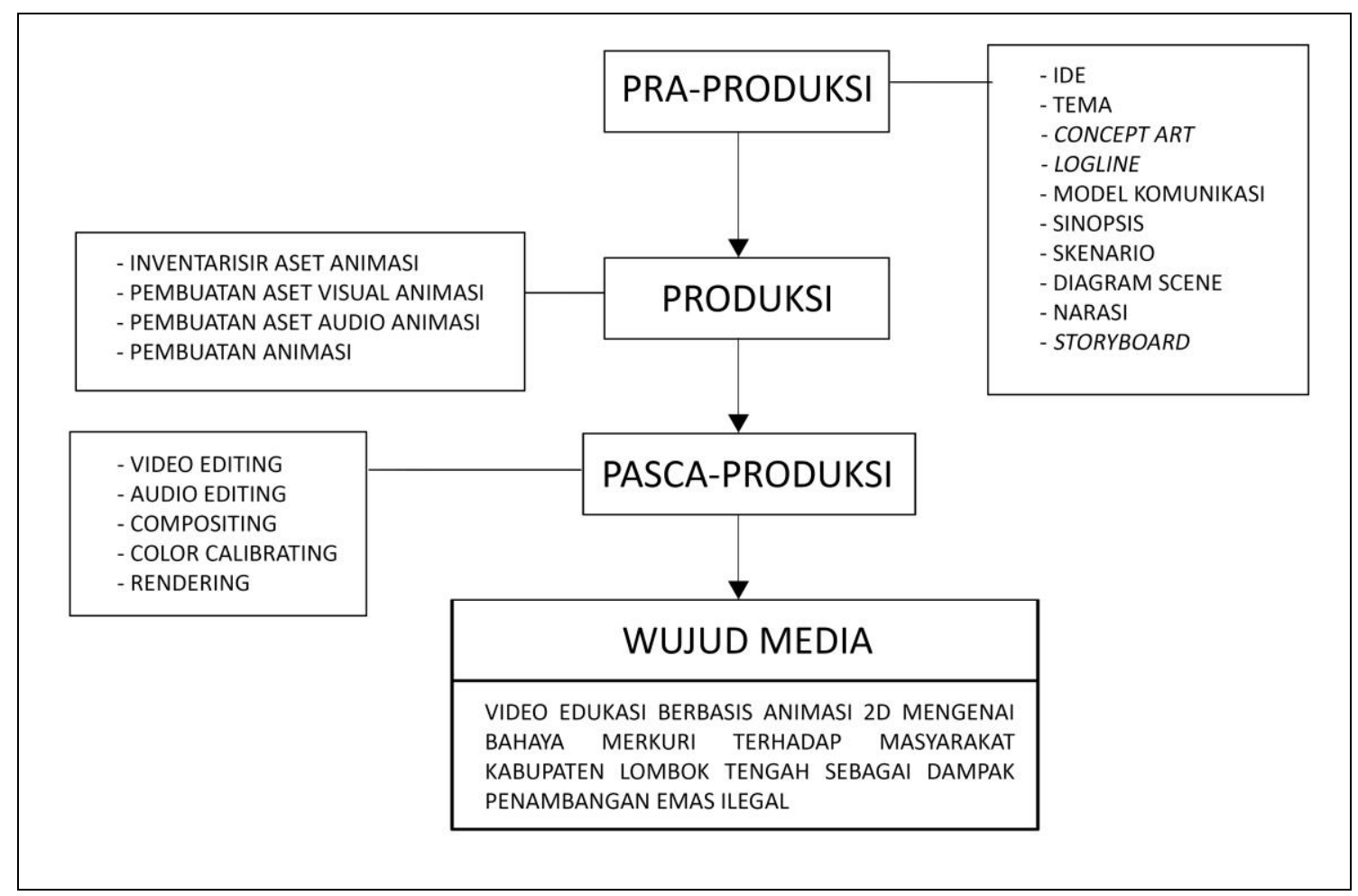

Gambar 1. Langkah metodologis perancangan animasi

Pengumpulan data primer dilakukan dengan observasi dan wawancara. Observasi dijalankan dalam aktivitas pengamatan langsung pada salah satu sentra pengolahan emas di Desa Prabu, Kecamatan Pujut, untuk mendapatkan informasi tentang proses kegiatan pengolahan emas menggunakan merkuri dan cara pengolahan limbah (Gambar2). 


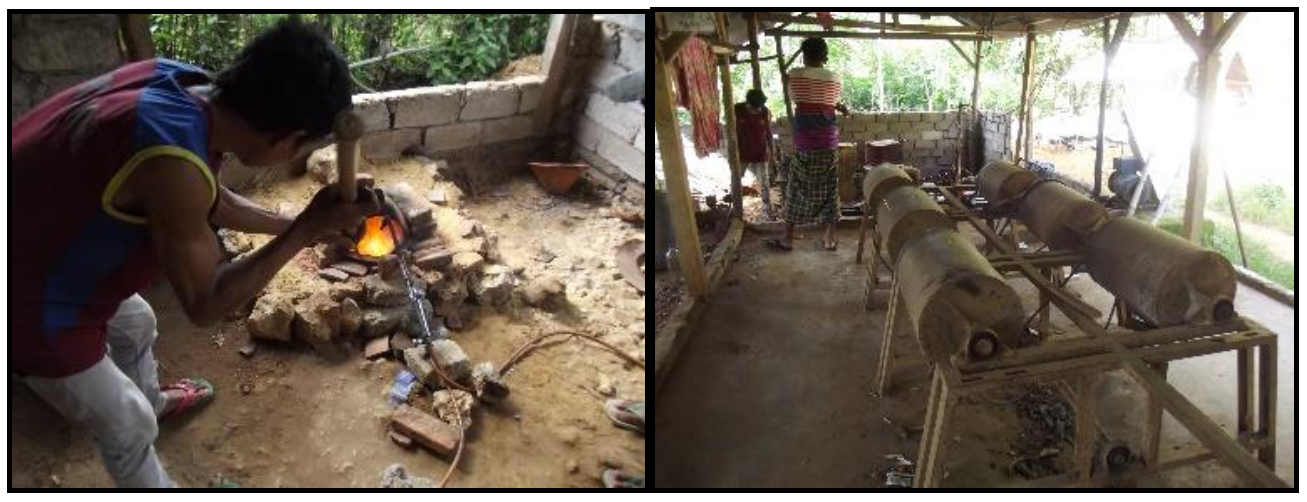

Gambar 2. Foto Kiri : Proses Pembakaran Tanpa Menggunakan APD

Foto Kanan : Gelondong

[sumber : dokumentasi Yusa dan Rukmi]

Wawancara dilakukan dengan Bapak Ir. Muhamad Nur Arif, M. Si, selaku Kepala Seksi Konservasi Sumber Daya Alam dan Bapak Lalu Ma'as Solihin, S.T., M. Eng selaku Kepala Seksi Pengawasan dan Pengendalian Lingkungan di Kantor Lingkungan Hidup Kabupaten Lombok Tengah. Beliau dipilih sebagai narasumber karena mengetahui dan dapat memberikan informasi-informasi yang dibutuhkan mengenai materi yang dibahas, seperti dampak pengolahan emas menggunakan merkuri terhadap lingkungan dan manusia. Wawancara juga dilakukan dengan Sukandi yang merupakan salah satu pengumpul dan pengolah emas menggunakan merkuri. Dari wawancara didapatkan data mengenai proses pengolahan emas dan sebaran pengetahuan pekerja atas dampak negatif merkuri bagi kesehatan.

Pengumpulan data sekunder dilakukan dengan dokumentasi dan studi literatur. Dokumentasi yang dilakukan adalah mengumpulkan hasil dokumentasi terdahulu mengenai kondisi kesehatan pekerja pengumpul emas di Lombok Tengah, dokumentasi foto proses pengolahan emas, dan foto proses sosialisasi yang dianggap menjenuhkan karena penyampaian materi monoton dan materi sosialisasi terlalu banyak menampilkan tulisan (Gambar 3).
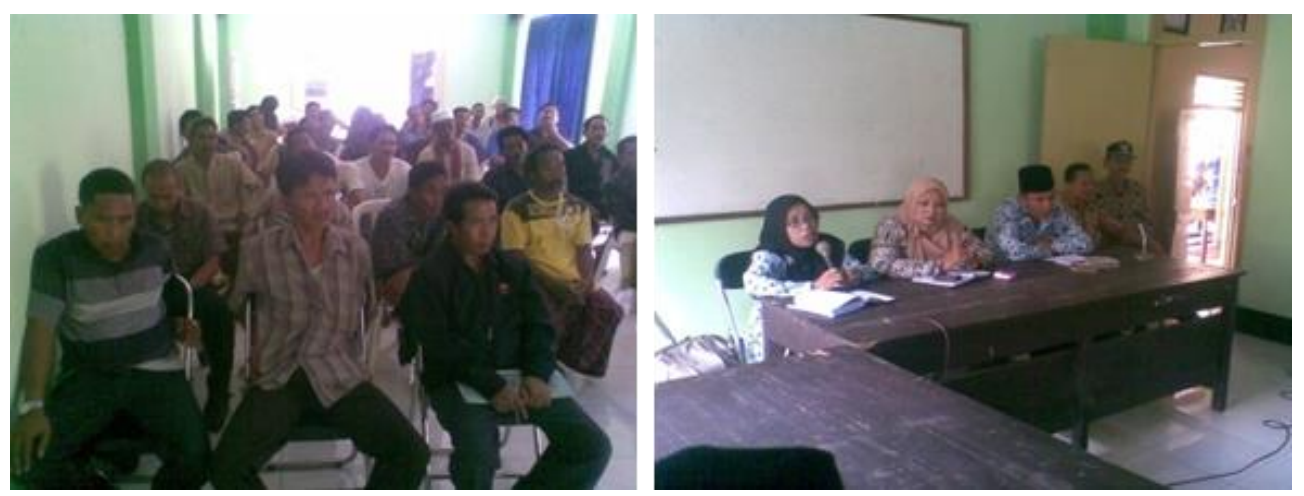

Gambar 3. Sosialisasi Penambangan Emas Ilegal Yang Dilakukan oleh Kantor Lingkungan Hidup Lombok Tengah di Kantor Desa Sintung [Sumber:Dokumentasi Kantor Lingkungan Hidup Lombok Tengah] 
Studi literatur dilakukan pada sumber pustaka yang terkait dengan bahaya Merkuri bagi kesehatan manusia, perancangan animasi 2 Dimensi, dan model komunikasi media digital. Animasi dirancang dengan adaptasi pendekatan model komunikasi SMCR yang menyampaikan materi dengan metode Health Belief Model.

\subsection{Health Belief Model}

Strecher, V.J. dan Rosenstock, I.M. (1997:113-117) mengungkap bahwa Health Belief Model adalah teori yang paling umum digunakan dalam pendidikan dan promosi kesehatan. Model ini dikembangkan pada tahun 1950-an sebagai cara untuk menjelaskan mengapa program skrining medis yang ditawarkan oleh layanan US Public Health, terutama terhadap penyakit TBC tidak sangat sukses. Konsep yang mendasari HBM awal adalah bahwa perilaku kesehatan ditentukan oleh keyakinan pribadi atau persepsi tentang penyakit dan strategi yang tersedia untuk mengurangi terjadinya masalah kesehatan.

Health Belief Model (disingkat HBM) seringkali dipertimbangkan sebagai kerangka utama dalam perilaku yang berkaitan dengan kesehatan manusia dan telah mendorong penelitian perilaku kesehatan sejak tahun 1950-an. Hal ini menjadikan HBM sebagai model yang menjelaskan pertimbangan seseorang sebelum mereka berperilaku sehat. Oleh karena itu, HBM memiliki fungsi sebagai model pencegahan atau preventif (Green dan Murphy, 2014).

\subsection{Sinopsis}

Video animasi ini akan menggambarkan proses pencemaran lingkungan oleh merkuri sebagai dampak penambangan emas ilegal di Kabupaten Lombok Tengah. Selain itu, juga menggambarkan bahaya merkuri terhadap kesehatan apabila telah terpapar merkuri dalam jangka waktu tertentu. Visualisasinya akan dimulai dari pengenalan umum tentang merkuri serta penggunaannya dalam industri pengolahan emas, proses pencemaran merkuri terhadap lingkungan, resiko kesehatan yang ditimbulkan serta data-data seputar merkuri dan penggunaannya di wilayah sentra pengolahan emas, khususnya di Kabupaten Lombok Tengah.

\subsection{Logline}

Melalui pengembangan ide, didapatkan logline "Lebih Baik Mencegah Daripada Mengobati". Pertimbangan pemilihan logline tersebut didasarkan pada kegiatan menambang emas yang telah dilakukan belum terlalu lama yakni sekitar 3-4 tahun sedangkan dampak dari keracunan merkuri sendiri membutuhkan waktu lebih dari 10 tahun. Oleh karena itu lebih baik mencegah risiko keracunan merkuri sejak dini dengan menghentikan aktivitas penambangan emas atau mengurangi intensitas kegiatan penambangan emas daripada merasakan dampak keracunan merkuri sebagai akibat penambangan emas ilegal.

\subsection{Gaya Visual Animasi}

Dalam video animasi pengenalan bahaya merkuri ini, penulis memilih adaptasi visualisasi flat design yang sederhana sebagai gaya visual secara umum. Konsep yang flat dapat dilihat dari unsur visual atau aset animasi yang tidak banyak menggunakan 
tekstur, efek-efek gradasi dan shading dengan brush stroke artistik. Konsep sederhana ini dapat dilihat penerapannya pada penggunaan ilustrasi dan huruf. Contoh konsep sederhana dalam penggunaan ilustrasi yakni penyederhanaan bentuk gambar, seperti ilustrasi manusia dimana biasanya memiliki detail yang kompleks, dalam animasi ini diilustrasikan sebagai sticky man. Sedangkan kesederhanaan dalam pemilihan huruf yakni menggunakan huruf yang tidak terlalu rumit dan mudah dibaca yakni GoBold Font dan Century Gothic. Selain itu juga dapat dilihat dalam penyampaian informasinya disampaikan dengan bahasa yang mudah dipahami.

\subsection{Ilustrasi}

Ilustrasi yang digunakan berupa ilustrasi digital vektor dan bitmap. Penulis memilih aset ilustrasi digital berbasis vektor untuk menampilkan visualisasi flat design. Pertimbangan selanjutnya, sisi bentuk ilustrasi digital vektor masih terlihat solid ketika diperbesar (zoom in), dan memudahkan pengerjaan aset di berbagai resolusi. Ilustrasi berbasis bitmap/raster digunakan untuk menyampaikan informasi yang harus disampaikan apa adanya, seperti ilustrasi foto yang mampu memberikan gambaran yang lebih realistis, sehingga lebih mudah dipahami oleh penonton.

\subsection{Warna}

Warna yang digunakan dalam pembuatan animasi tersebut adalah warna primer, sekunder dan tersier sesuai dengan definisinya. Untuk warna objek utama yakni merkuri akan menggunakan warna aslinya yaitu perak/ silver, warna ini dipilih karena menimbulkan kesan yang merusak. Selain itu warna dominan yang digunakan adalah warna coklat dan hijau dengan pertimbangan coklat merupakan warna bumi dan memberikan efek psikologis yang nyaman, dan hijau memiliki arti yang alami, kesehatan.

\subsection{Tipografi}

Jenis huruf yang dipilih adalah Sans Serif dengan pendekatan tampilan karakteristik non formal. Font yang digunakan adalah font Gobold dan Century Gothic. Font Gobold dipilih karena memiliki kesan yang tegas, dilihat dari bentuk normal hurufnya yang cenderung bold (tebal). Karakteristik tersebut berguna untuk menegaskan tulisan yang dianggap penting. Sedangkan font Century Gothic memiliki kesan yang lebih santai dan sederhana, sehingga cocok untuk menjelaskan keterangan atau pesan yang bersifat mendukung.

\subsection{Storyboard}

Storyboard yang dirancang merupakan pengejawantahan naskah-skenario dan diagram scene yang telah disusun sebelumnya (Tabel 1 ). 
Tabel 1. Storyboard Video Animasi 2 Dimensi Mengenai Bahaya Merkuri Terhadap Masyarakat Kabupaten Lombok Tengah Sebagai Dampak Dari Penambangan Emas Ilegal

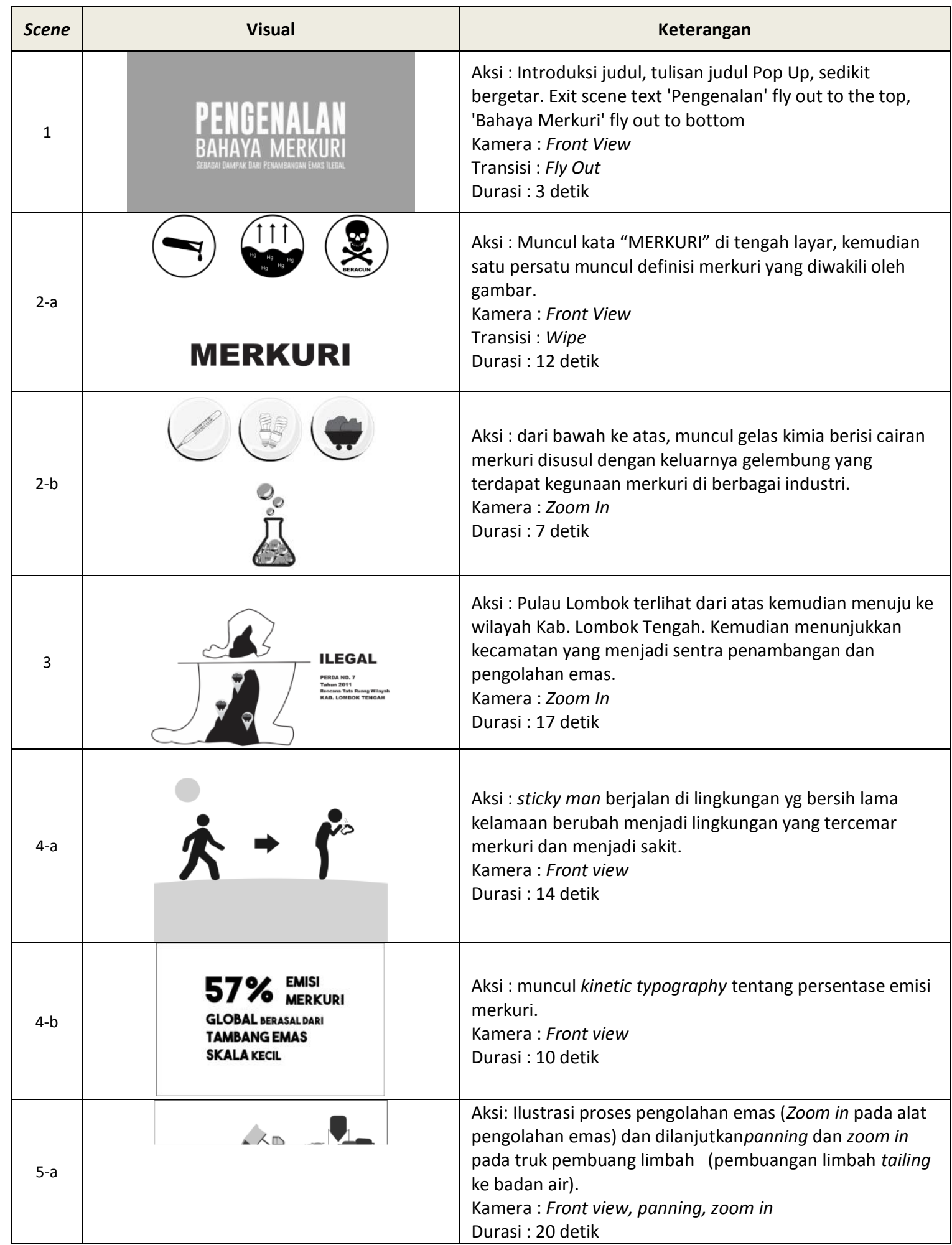




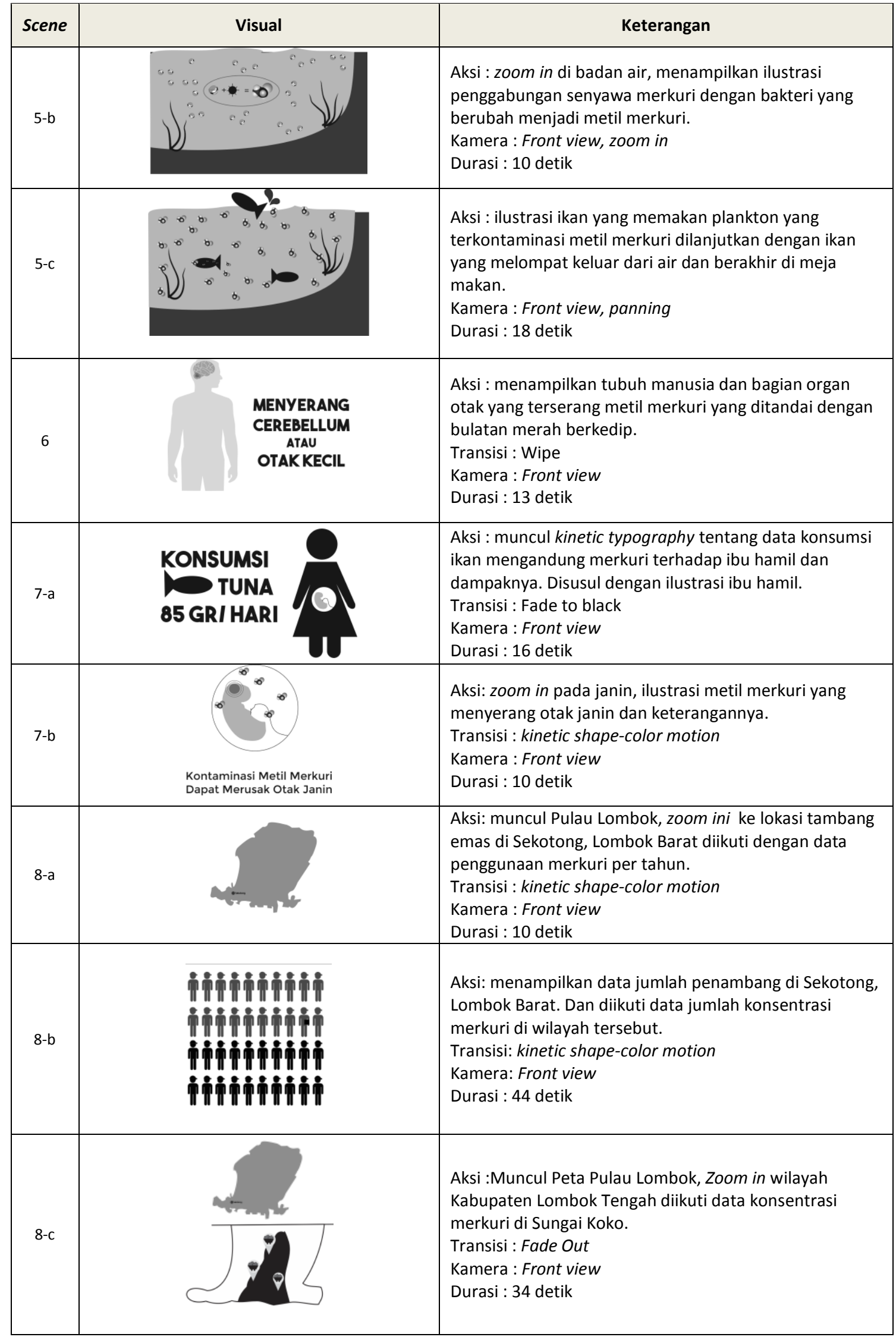




\begin{tabular}{|c|l|l|}
\hline Scene & \multicolumn{1}{|c|}{ Visual } & \multicolumn{1}{|c|}{ Keterangan } \\
\hline 9 & & $\begin{array}{l}\text { Aksi : Menampilkan berbagai contoh kasus keracunan } \\
\text { merkuri. } \\
\text { Transisi : Fade out } \\
\text { Kamera : Front view } \\
\text { Durasi : 10 detik }\end{array}$ \\
\hline 10 & & $\begin{array}{l}\text { Aksi : muncul red cross, mengeluarkan gulungan pita } \\
\text { dengan tulisan “Lebih Baik Mencegah Daripada } \\
\text { Mengobati". } \\
\text { Transisi : Push Left } \\
\text { Kamera : Front View } \\
\text { Durasi : 3 detik }\end{array}$ \\
\hline
\end{tabular}

\subsection{Evaluasi Video Animasi}

Penelitian ini dilakukan dengan menggunakan pendekatan kualitatif. Penjabaran data kualitatif berdasarkan data kuantitatif yang diperoleh saat pengujian dengan menggunakan metode kuesioner ditambah dengan hasil wawancara. Hasil dari pengolahan data bertujuan untuk mengetahui tingkat kelayakan video animasi 2D pengenalan bahaya merkuri terhadap manusia sebagai dampak penambangan emas ilegal di Kabupaten Lombok Tengah untuk ditayangkan. Metode kuesioner menggunakan skala pengukuran model skala Likert. Skala pengukuran merupakan kesepakatan yang digunakan sebagai acuan menentukan panjang pendeknya interval yang ada dalam alat ukur sehingga alat ukur tersebut bila digunakan dalam pengukuran akan menghasilkan data kuantitatif (Sugiyono, 2013).

\subsection{Skala Likert}

Skala Likert merupakan teknik pengukuran sikap dimana subjek diminta untuk mengindikasikan tingkat kesetujuan mereka terhadap masing-masing pernyataan (Sugiyono, 2013). Skala Likert secara matematis dapat dijelaskan dalam rumus berikut ini.

$$
\mathrm{P}=\frac{\mathrm{fx} 100 \%}{\mathrm{~N}}
$$

Keterangan :

$P$ : Presentase

$f$ : Frekuensi / Jumlah

$\mathrm{N}$ : Jumlah Sampel

Sugiyono (2013) juga mengungkapkan, setelah mendapatkan hasil pengukuran dengan skala Likert maka akan dilakukan tabulasi kategori atas tanggapan responden, dengan rumus sebagai berikut :

$$
\mathrm{K}=\mathrm{f} / \mathrm{N}
$$

Keterangan :

$\mathrm{K}$ : Angka Kategori

$\mathrm{F}$ : Jumlah Poin Likert $\quad \mathrm{N}$ : Jumlah Sampel 
Adapun pertanyaan yang diajukan dapat dilihat pada tabel 2 .

Tabel 2. Daftar Pernyataan Evaluasi Hasil Perancangan

\begin{tabular}{|c|c|c|c|c|c|c|}
\hline No & Pernyataan & SS & $\mathbf{S}$ & $\mathbf{N}$ & TS & STS \\
\hline 1 & $\begin{array}{l}\text { Informasi/ penjelasan tentang merkuri dalam } \\
\text { animasi ini tersampaikan dengan jelas. }\end{array}$ & & & & & \\
\hline 2 & $\begin{array}{l}\text { Pesan dan informasi tentang bahaya merkuri } \\
\text { sebagai dampak penambanagan emas ilegal } \\
\text { melalui video animasi ini sudah tersampaikan } \\
\text { dengan baik. }\end{array}$ & & & & & \\
\hline 3 & $\begin{array}{l}\text { Ilustrasi resiko keracunan yang diakibatkan } \\
\text { merkuri dapat dipahami. }\end{array}$ & & & & & \\
\hline 4 & $\begin{array}{l}\text { Video animasi pengenalan bahaya merkuri yang } \\
\text { sudah ditayangkan menarik untuk ditonton. }\end{array}$ & & & & & \\
\hline 5 & $\begin{array}{l}\text { Informasi tulisan pada video animasi mudah } \\
\text { terbaca. }\end{array}$ & & & & & \\
\hline 6 & Suara narator dalam video ini terdengar jelas. & & & & & \\
\hline 7 & $\begin{array}{l}\text { Video animasi ini direkomendasikan untuk } \\
\text { ditayangkan dan didistribusikan. }\end{array}$ & & & & & \\
\hline
\end{tabular}

Keterangan : SS (Sangat Setuju), S (Setuju), N (Netral), TS (Tidak Setuju), STS (Sangat Tidak Setuju)

\section{HASIL DAN PEMBAHASAN}

\subsection{Hasil Video Animasi}

Pada tabel 3 ditampilkan preview video animasi final yang diwakilkan dengan screen shot preview yang mewakili tiap scene.

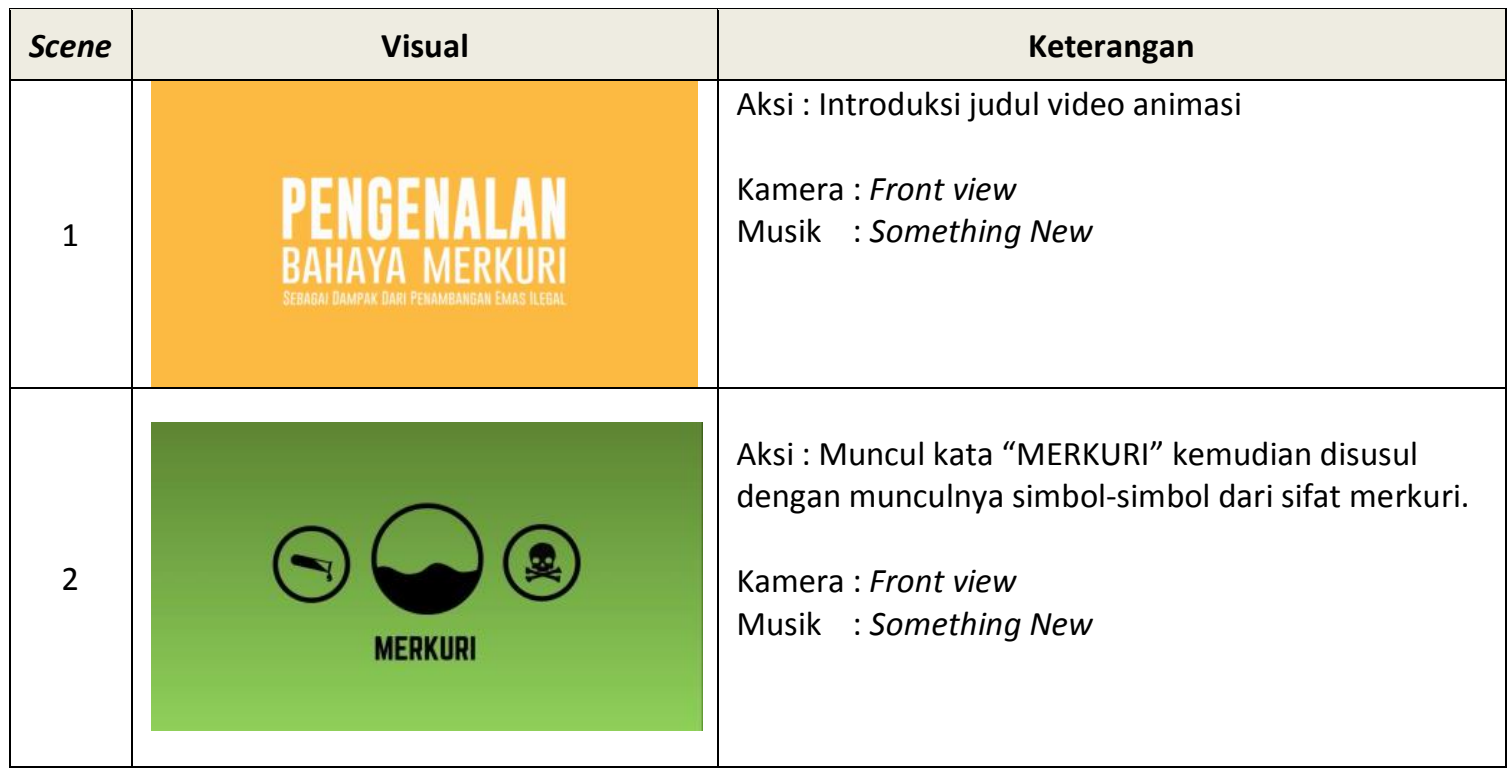




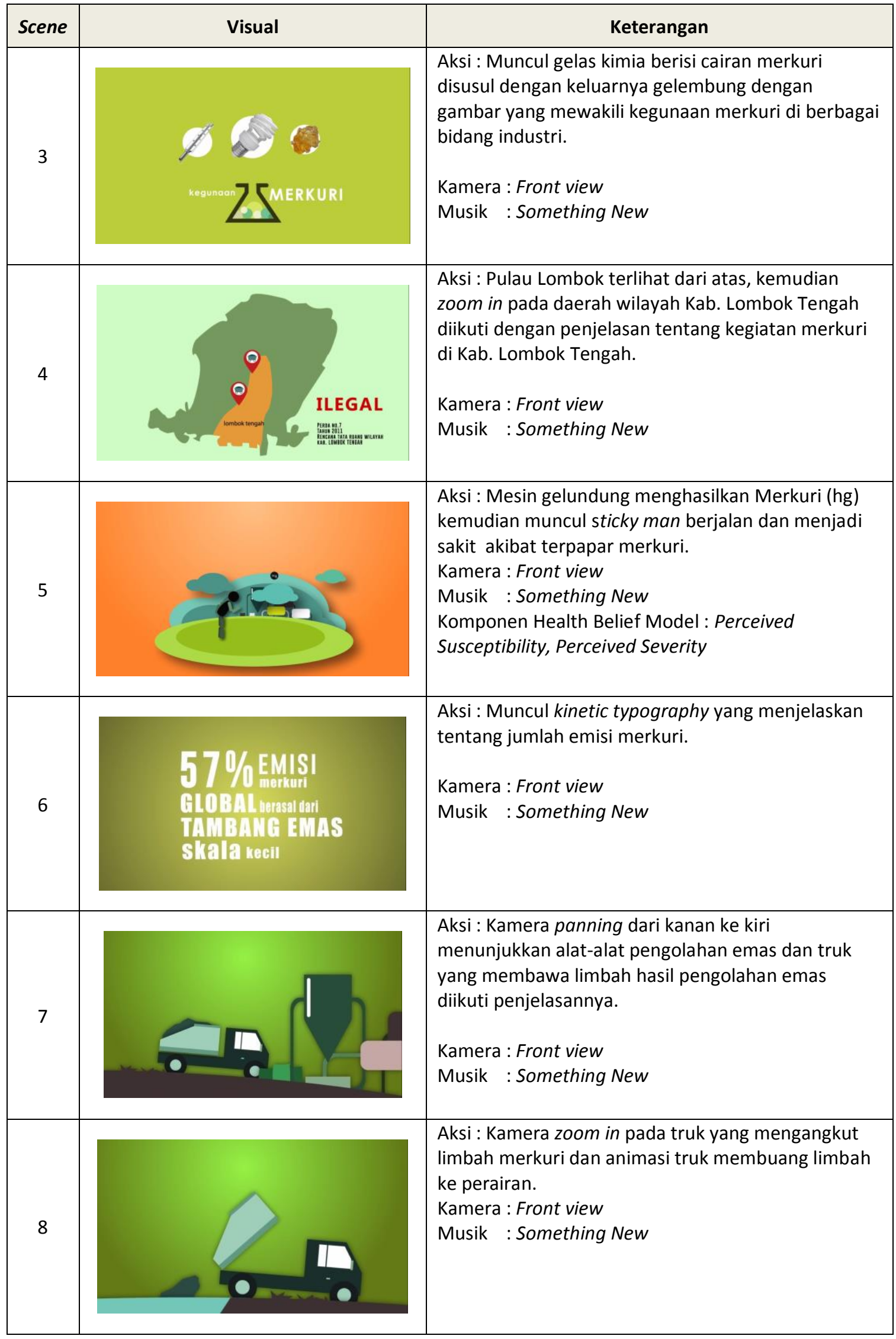




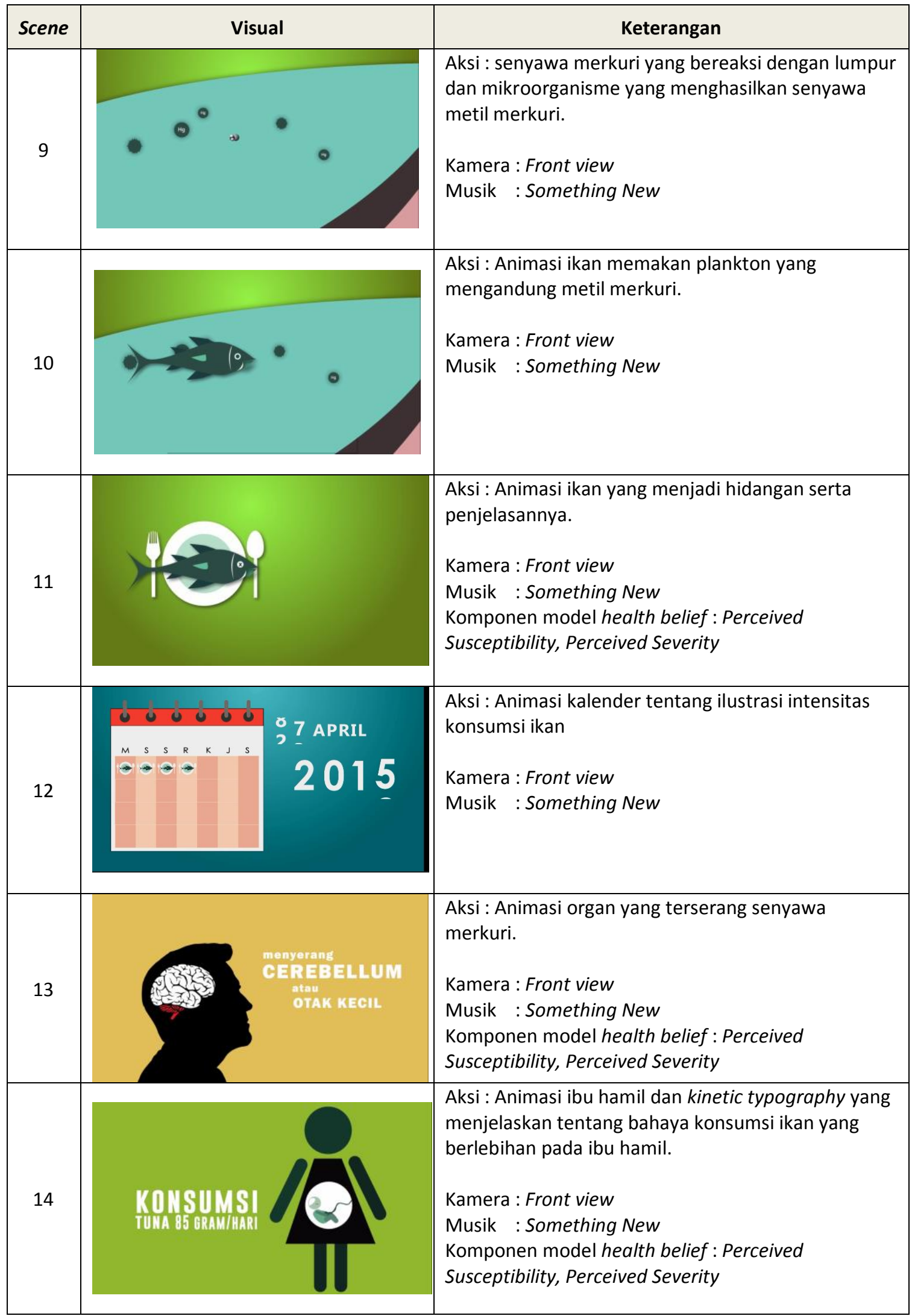




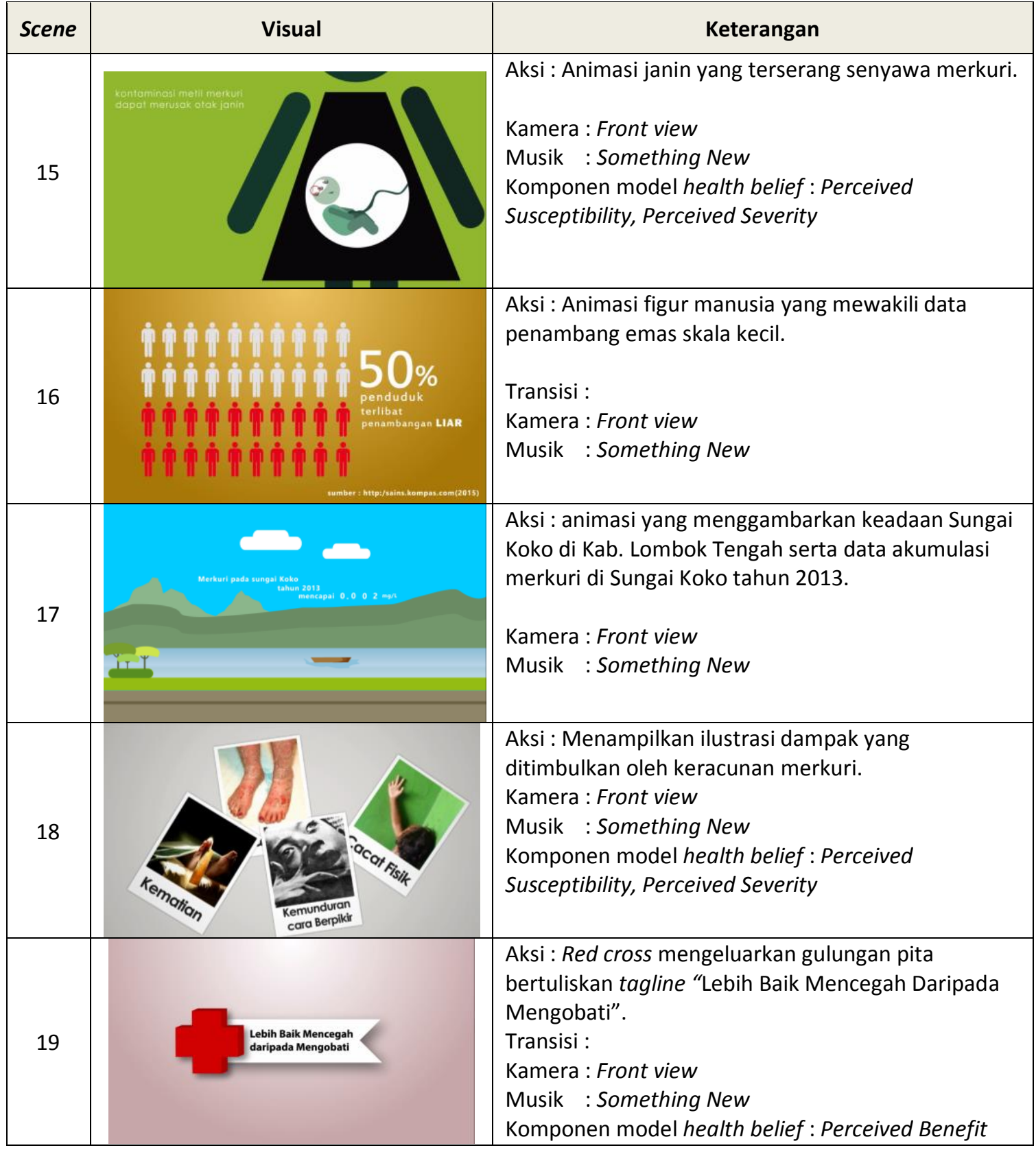

\subsection{Implementasi Model Komunikasi Health Belief}

Pada Scene 05 ditampilkan animasi orang berjalan (direpresentasikan dengan stickman) yang berubah kondisinya menjadi sakit setelah melewati lokasi pengolahan emas ilegal yang menghasilkan limbah merkuri. Komponen Health Belief Model yang digunakan adalah Perceived Susceptibility, yaitu kepercayaan seseorang dengan menganggap menderita penyakit adalah hasil melakukan perilaku tertentu. Perceived susceptibility juga diartikan sebagai perceived vulnerability yang berarti kerentanan yang dirasakan, merujuk pada kemungkinan seseorang dapat terkena suatu penyakit. Perceived susceptibility ini memiliki hubungan positif dengan perilaku sehat. Jika persepsi kerentanan terhadap penyakit tinggi maka perilaku sehat yang dilakukan seseorang juga tinggi. Model komunikasi dengan komponen ini disampaikan dengan 
mengilustrasikan perubahan kesehatan individu yang memburuk/menurun jika dalam jangka waktu lama terpapar merkuri. Scene 05 mengedukasi audience bahwa semakin sering seseorang berada di lingkungan tidak sehat, semakin tinggi peluangnya untuk menjadi sakit, sebagai hasil menjalankan aktivitas pengolahan emas ilegal. Pendekatan Perceived Susceptibility ini juga disampaikan pada scene 11, 13, 14, 15, dan 18.

Komponen yang selanjutnya juga mendukung adalah perceived severity. Perceived severity adalah kepercayaan subyektif individu dalam menyebarnya penyakit yang disebabkan oleh perilaku, atau percaya seberapa berbahayanya penyakit sehingga menghindari perilaku tidak sehat agar tidak sakit. Hal ini berarti perceived severity berprinsip pada persepsi atas tingkat keparahan yang akan diterima individu. Perceived severity juga memiliki hubungan yang positif dengan perilaku sehat. Jika persepsi keparahan individu tinggi, maka ia akan berperilaku sehat. Pendekatan model ini yang dominan diterapkan pada video animasi dengan memaparkan data pendukung dan fakta untuk memberikan kepastian pada audience bahwa dampak yang dihadapi sangat nyata. Pendekatan Perceived Severity disampaikan pada scene yang sama dengan pendekatan Perceived Susceptibility yaitu pada scene 5, 11, 13, 14, 15, dan 18.

Pendekatan perceived Benefits disampaikan dalam penutup untuk mencoba mengajak audience melihat peluang untuk menjadi sehat, dalam situasi dan lingkungan yang tidak kondusif. Poin utama yang disampaikan adalah mengutamakan tindakan preventif atau pencegahan, dibanding pengobatan. Perceived benefits adalah kepercayaan terhadap keuntungan dari metode yang disarankan untuk mengurangi resiko penyakit. Perceived benefits secara ringkas berarti persepsi keuntungan yang memiliki hubungan positif dengan perilaku sehat. Individu yang sadar akan keuntungan deteksi dini penyakit akan terus melakukan perilaku sehat seperti medical check up rutin. Pendekatan ini disampaikan pada scene 19 sebagai scene penutup.

Dalam penyampaian message (pesan) pada video animasi yang mengombinasikan dengan model komunikasi SMCR, pihak yang bertanggung jawab dalam menyosialisasikan materi (Dinas Lingkungan Hidup Kabupaten Lombok Tengah) sebagai source (Sumber) berperan dalam komponen Cues to Action pada health belief model. Cues to action adalah mempercepat tindakan yang membuat seseorang merasa butuh mengambil tindakan atau melakukan tindakan nyata untuk melakukan perilaku sehat. Cues to action juga berarti dukungan atau dorongan dari lingkungan terhadap individu yang melakukan perilaku sehat. Source bertanggungjawab dalam mengondisikan, memotivasi receiver/audience untuk segera melakukan tindakan preventif.

\subsection{Hasil Pengujian}

Setelah video selesai, tahapan selanjutnya adalah melakukan pengujian untuk mengetahui seberapa layak video animasi pengenalan bahaya merkuri ini dijadikan sebagai media sosialisasi yang dilakukan oleh pihak Kantor Lingkungan Hidup Kabupaten Lombok Tengah. Pengujian melibatkan responden yang ditentukan dengan metode Purposive Sampling. Metode ini dilakukan dengan pengambilan sampel sesuai dengan persyaratan sampel yang diperlukan. Responden berjumlah total 30 orang, 
sesuai dengan jumlah keseluruhan pegawai, dimana 15 orang dari bagian Konservasi Sumber Daya Alam dan 15 orang lagi dari bagian Pengawasan dan Pengendalian Lingkungan Hidup. Kedua bagian tersebut adalah bagian yang bertanggung jawab dalam melakukan sosialisasi. Pengujian dilakukan dengan memberikan beberapa pertanyaan melalui kuesioner. Adapun data yang diperoleh dapat dilihat pada tabel 4.

Tabel 4. Hasil Pengujian Video Animasi 2 Dimensi

Pengenalan Bahaya Merkuri Terhadap Masyarakat Kabupaten Lombok Tengah Sebagai Dampak Dari Penambangan Emas Ilegal

\begin{tabular}{|c|c|c|c|c|c|}
\hline No. & Pernyataan & Jawaban & Jumlah & $\begin{array}{c}\text { Frekuensi } \\
\text { (\%) }\end{array}$ & Poin \\
\hline \multirow[t]{5}{*}{1} & \multirow{5}{*}{$\begin{array}{l}\text { Informasi/ penjelasan } \\
\text { tentang merkuri dalam } \\
\text { animasi ini tersampaikan } \\
\text { dengan jelas }\end{array}$} & $\begin{array}{l}\text { Sangat } \\
\text { Setuju }\end{array}$ & 18 & $60 \%$ & 90 \\
\hline & & Setuju & 12 & $40 \%$ & 48 \\
\hline & & Netral & 0 & 0 & 0 \\
\hline & & $\begin{array}{l}\text { Tidak } \\
\text { Setuju } \\
\end{array}$ & 0 & 0 & 0 \\
\hline & & $\begin{array}{l}\text { Sangat } \\
\text { Tidak } \\
\text { Setuju }\end{array}$ & 0 & 0 & 0 \\
\hline \multicolumn{5}{|c|}{ Jumlah Poin } & 138 \\
\hline \multirow{5}{*}{2} & \multirow{5}{*}{$\begin{array}{l}\text { Pesan dan informasi } \\
\text { tentang bahaya merkuri } \\
\text { sebagai dampak } \\
\text { penambanagan emas ilegal } \\
\text { melalui video animasi ini } \\
\text { sudah tersampaikan } \\
\text { dengan baik. }\end{array}$} & $\begin{array}{l}\text { Sangat } \\
\text { Setuju }\end{array}$ & 12 & $40 \%$ & 60 \\
\hline & & Setuju & 18 & $60 \%$ & 72 \\
\hline & & Netral & 0 & 0 & 0 \\
\hline & & $\begin{array}{l}\text { Tidak } \\
\text { Setuju }\end{array}$ & 0 & 0 & 0 \\
\hline & & $\begin{array}{l}\text { Sangat } \\
\text { Tidak } \\
\text { Setuju }\end{array}$ & 0 & 0 & 0 \\
\hline \multicolumn{5}{|c|}{ Jumlah Poin } & 132 \\
\hline \multirow{5}{*}{3} & \multirow{5}{*}{$\begin{array}{l}\text { Ilustrasi resiko keracunan } \\
\text { yang diakibatkan merkuri } \\
\text { dapat dipahami. }\end{array}$} & $\begin{array}{l}\text { Sangat } \\
\text { Setuju }\end{array}$ & 18 & $60 \%$ & 90 \\
\hline & & Setuju & 6 & $20 \%$ & 24 \\
\hline & & Netral & 6 & $20 \%$ & 18 \\
\hline & & $\begin{array}{l}\text { Tidak } \\
\text { Setuju } \\
\end{array}$ & 0 & 0 & 0 \\
\hline & & $\begin{array}{l}\text { Sangat } \\
\text { Tidak } \\
\text { Setuju }\end{array}$ & 0 & 0 & 0 \\
\hline \multicolumn{5}{|c|}{ Jumlah Poin } & 132 \\
\hline \multirow{4}{*}{4} & \multirow{4}{*}{$\begin{array}{l}\text { Video animasi pengenalan } \\
\text { bahaya merkuri yang } \\
\text { sudah ditayangkan } \\
\text { menarik untuk ditonton. }\end{array}$} & $\begin{array}{l}\text { Sangat } \\
\text { Setuju }\end{array}$ & 9 & $30 \%$ & 45 \\
\hline & & Setuju & 15 & $50 \%$ & 60 \\
\hline & & Netral & 6 & $20 \%$ & 18 \\
\hline & & $\begin{array}{l}\text { Tidak } \\
\text { Setuju }\end{array}$ & 0 & 0 & 0 \\
\hline
\end{tabular}




\begin{tabular}{|c|c|c|c|c|c|}
\hline No. & Pernyataan & Jawaban & Jumlah & $\begin{array}{c}\text { Frekuensi } \\
\text { (\%) }\end{array}$ & Poin \\
\hline & & $\begin{array}{l}\text { Sangat } \\
\text { Tidak } \\
\text { Setuju }\end{array}$ & 0 & 0 & 0 \\
\hline \multicolumn{5}{|c|}{ Jumlah Poin } & 123 \\
\hline \multirow{5}{*}{5} & \multirow{5}{*}{$\begin{array}{l}\text { Informasi tulisan pada } \\
\text { video animasi mudah } \\
\text { terbaca. }\end{array}$} & $\begin{array}{l}\text { Sangat } \\
\text { Setuju }\end{array}$ & 9 & $30 \%$ & 45 \\
\hline & & Setuju & 18 & $60 \%$ & 54 \\
\hline & & Netral & 3 & $10 \%$ & 9 \\
\hline & & $\begin{array}{l}\text { Tidak } \\
\text { Setuju }\end{array}$ & 0 & 0 & 0 \\
\hline & & $\begin{array}{l}\text { Sangat } \\
\text { Tidak } \\
\text { Setuju }\end{array}$ & 0 & 0 & 0 \\
\hline \multicolumn{5}{|c|}{ Jumlah Poin } & 108 \\
\hline \multirow{5}{*}{6} & \multirow[t]{5}{*}{$\begin{array}{l}\text { Suara narator dalam video } \\
\text { ini terdengar jelas. }\end{array}$} & $\begin{array}{l}\text { Sangat } \\
\text { Setuju }\end{array}$ & 9 & $30 \%$ & 45 \\
\hline & & Setuju & 21 & $70 \%$ & 84 \\
\hline & & Netral & 0 & 0 & 0 \\
\hline & & $\begin{array}{l}\text { Tidak } \\
\text { Setuju }\end{array}$ & 0 & 0 & 0 \\
\hline & & $\begin{array}{l}\text { Sangat } \\
\text { Tidak } \\
\text { Setuju }\end{array}$ & 0 & 0 & 0 \\
\hline \multicolumn{5}{|c|}{ Jumlah Poin } & 129 \\
\hline \multirow{5}{*}{7} & \multirow{5}{*}{$\begin{array}{l}\text { Video animasi ini } \\
\text { direkomendasikan untuk } \\
\text { ditayangkan dan } \\
\text { didistribusikan. }\end{array}$} & $\begin{array}{l}\text { Sangat } \\
\text { Setuju }\end{array}$ & 18 & $60 \%$ & 90 \\
\hline & & Setuju & 12 & $40 \%$ & 48 \\
\hline & & Netral & 0 & 0 & 0 \\
\hline & & $\begin{array}{l}\text { Tidak } \\
\text { Setuju }\end{array}$ & 0 & 0 & 0 \\
\hline & & $\begin{array}{l}\text { Sangat } \\
\text { Tidak } \\
\text { Setuju }\end{array}$ & 0 & 0 & 0 \\
\hline \multicolumn{5}{|c|}{ Jumlah Poin } & 138 \\
\hline
\end{tabular}

Berdasarkan hasil kuisioner diatas, dapat disimpulkan bahwa video animasi pengenalan bahaya merkuri terhadap masyarakat Kabupaten Lombok Tengah sebagai dampak dari penambangan emas ilegal sudah layak dari segi informasi maupun desain dan direkomendasikan untuk ditayangkan serta didistribusikan sebagai media bantu sosialisasi tentang bahaya merkuri ke masyarakat Kabupaten Lombok Tengah, khususnya masyarakat di sekitar sentra pengolahan emas di Kabupaten Lombok Tengah.

\section{KESIMPULAN}

Perancangan video animasi ini menjalankan langkah metodologis dan prosedur standar perancangan animasi 2 dimensi dengan menggunakan teknik-teknik perancangan 
animasi yang didapat dari teori-teori lalu diimplementasikan saat pembuatan animasi. Dalam perancangan video animasi ini melewati tahapan-tahapan pra produksi yang meliputi penentuan ide, tema, concept art, logline, menyiapkan naskah hingga storyboard. Tahap selanjutnya adalah tahap produksi yang meliputi pembuatan aset audio-visual animasi serta penganimasian. Tahap pasca produksi meliputi editing video dan audio, compositing, color calibrating, serta rendering hingga didapatkan hasil akhir yang siap untuk dipublikasikan.

Melalui model komunikasi yang mengombinasikan model SMCR dengan model health belief, video animasi ini mengandung nilai edukasi dan persuasi untuk mengajak audience melakukan langkah preventif dalam menjaga kesehatannya. Video animasi ini akan digunakan oleh Dinas Lingkungan Hidup Kabupaten Lombok Tengah dalam menyosialisasikan bahaya merkuri kepada masyarakat Lombok Tengah.

Menurut hasil uji kuesioner terhadap 30 orang responden yang diambil berdasarkan metode purposive sampling dapat disimpulkan sebagai berikut:

a. Penyampaian informasi mengenai merkuri dan bahayanya yang terdapat pada poin pertama dan kedua sudah tersampaikan dengan baik dan jelas.

b. Video animasi ini sudah menarik untuk ditonton.

c. Tulisan dan audio yang terdapat pada video animasi (terungkap pada poin ke-lima dan ke-enam di kuesioner) sudah terbaca dan terdengar dengan jelas.

d. Video animasi ini direkomendasikan untuk ditayangkan dan didistribusikan.

\section{Saran}

Masyarakat Lombok Tengah wajib memahami arti pentingnya kesehatan dan pekerjaan legal, khususnya dalam penambangan, dan pengolahan emas. Issue ini perlu terus disosialisasikan oleh pihak yang bertanggungjawab, dalam hal ini Dinas Lingkungan Hidup Kabupaten Lombok Tengah. Wujud media sosialisasi harus mendapat perhatian ekstra karena menentukan diterima atau tidaknya pesan oleh audience dalam proses sosialisasi. Media video animasi 2D ini berhasil memberikan wawasan dan pengalaman estetik baru bagi masyarakat Lombok Tengah. Pengembangan media sosialisasi dalam bentuk lain yang lebih baik memiliki peluang penciptaan dan pengembangan yang sangat terbuka luas. Peneliti selanjutnya dapat menyajikan video animasi tentang bahaya merkuri dengan lebih baik dan lebih interaktif, misalnya dalam bentuk multimedia interaktif berbasis desktop atau mobile, video animasi 3D atau mungkin media dengan teknologi termutakhir seperti video mapping, augmented reality, atau virtual reality. Pendekatan penyampaian pesan juga bisa dikembangkan, misalnya dengan mengeksplorasi konsep digital storytelling. Selain itu perlu juga dilakukan kajian lebih dalam lagi tentang merkuri dan bahayanya, baik terhadap lingkungan maupun manusia sehingga informasi yang disajikan lebih lengkap. Juga perlu dilakukan kajian yang lebih mendalam lagi terhadap teori unsur-unsur visual agar mendapatkan kesesuaian antara desain dengan konsep pesan yang ingin disampaikan. 


\section{DAFTAR PUSTAKA}

Blair, P. 1994. Cartoon Animation.

Green, E. C., \& Murphy, E. 2014. Health belief model. The Wiley Blackwell encyclopedia of health, illness, behavior, and society.

Palar, H. 2012. Pencemaran dan Toksikologi Logam Berat.

Purnama, B. E. 2013. Konsep Dasar Multimedia. Yogyakarta: Graha IImu.

Saputro, G. E., Haryadi, T., \& Yanuarsari, D. H. 2016. Perancangan Purwarupa Komik Interaktif Safety Riding Berkonsep Digital Storytelling. ANDHARUPA, 2(02), 195-206.

Sitepu, M. 2004. Merkuri dan Bahayanya bagi Kesehatan. Jakarta: Info Pom, 5(04).

Sitepu, V. 2005. Membuat Animasi Alam dengan Corel Bryce. Elex Media.

Strecher, V. J., \& Rosenstock, I. M. 1997. The health belief model. Cambridge handbook of psychology, health and medicine, 113-117.

Subanri, S. 2008. Kajian Beban Pencemaran Merkuri (Hg) Terhadap Air Sungai Menyuke Dan Gangguan Kesehatan Pada Penambang Sebagai Akibat Penambangan Emas Tanpa Izin (Peti) Di Kecamatan Menyuke Kabupaten Landak Kalimantan Barat (Doctoral dissertation, Universitas Diponegoro).

Sugiyono. 2013. Metode Penelitian Kuantitatif, Kualitatif dan R\&D.

Thomas, F. and Johnston, O. 1995. The Illusion of Life : Disney animation. New York : Hyperion

Yusa, I. M. M., \& Saputra, I. P. S. 2016. Pemanfaatan Animasi 2 Dimensi Model Infografik dalam Perancangan Video Iklan Layanan Masyarakat Tentang Pengolahan Sampah Rumah Tangga di Denpasar. Jurnal Nasional Pendidikan Teknik Informatika (Janapati), 5(1), 1-10.

Yusa, I.M.M. 2016. Sinergi Sains, Teknologi Dan Seni : Dalam Proses Berkarya Kreatif Di Dunia Teknologi Informasi. STIMIK STIKOM INDONESIA.

Yusa, I.M.M. 2017. Illustrating Zodiac. An1mage 